\title{
Supporting Identity Development in Cross-Cultural Children and Young People: Resources, Vulnerability, Creativity
}

\author{
Hildegunn Schuff \\ Ansgar Høgskole/ABUP, Sørlandet Sykehusi \\ schuff@ansgarskolen.no
}

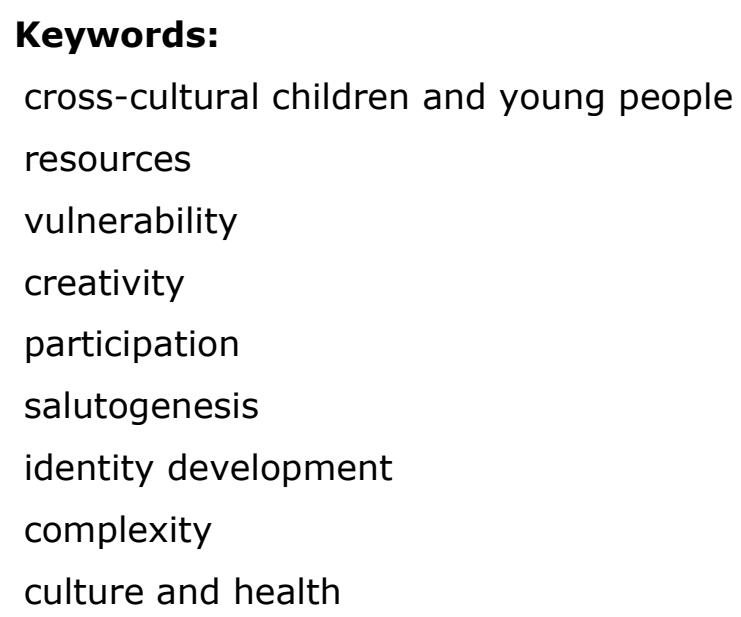




\begin{abstract}
Children and young people with cross-cultural backgrounds are significantly influenced by multiple cultures during their upbringing. They face the ambivalence and challenges of regularly dealing with multiple cultural frames of reference, norms and expectations, and often experience particular identity challenges. One might say that much of the ambivalence of modern intercultural societies may show up as internalized ambivalence in these "children of migration".
\end{abstract}

This article explores cross-cultural identity development. The aim is to further our understanding of how the identities of cross-cultural children and young people can be supported and their resources activated. This can both strengthen their resilience and wellbeing, and be of great value to society at large. Psychosocial/cultural interventions and creative projects in cross-cultural settings are potential arenas for this type of cultural health promotion. One example is the multicultural music project Fargespill ('Kaleidoscope'). In a case study of Kaleidoscope, I describe and discuss how these participatory creative activities work, and ask how they may foster the development of constructive cross-cultural identities. Participant observation was conducted in Kaleidoscope throughout a year. In the light of theoretical perspectives from social and cultural psychology, the article analyzes identity issues and possibilities within this empirical context.

Supporting cross-cultural identity development in a constructive manner is here operationalized as allowing, increasing and acknowledging identity complexity. The findings are categorized under the headings of resources, vulnerability and creativity. The project leaders make an effort to establish trust and a safe, supportive space. They apply a participatory method, in which the participants are seen as resources and their strengths and contributions are emphasized. In some situations, the vulnerability that may be caused by potentially being stereotyped is apparent, and identity definitions and complexities need to be negotiated. There are explicit expectations concerning creativity in the Kaleidoscope process, and the crossing of different cultural expressions, old and sometimes new, leads to the final creative product of the performance.

To summarize, identity complexity is given space to play out, relating to both origins and current participation in culture in construction here in Norwegian society. Thus, at its best, Kaleidoscope sets the stage for a flexible and playful performance of identity. This may be one path towards appreciated and integrated intercultural identities. 
In our globalized day and age, with ever increasing mobility across national and cultural borders, more and more children and young people are significantly influenced by multiple cultures during their upbringing. Whether they are immigrants or refugees themselves, the children of expatriates or of parents from different countries, they face the ambivalence and challenges of dealing regularly with multiple cultural frames of reference, norms and expectations. One might say that much of the ambivalence of modern intercultural societies may materialize as internalized ambivalence in these "children of migration".

Leading a cross-cultural life gives rise to various forms of negotiated hybrid identities. It often brings with it the challenges and burdens of being in a visible or invisible minority position, and can also cause vulnerability in relation to health. On the other hand, the complexity of these children's and young people's experience also endows them with particular multicultural competencies and flexibility that may enable them to act as cultural interpreters, who are much needed in modern globalized societies.

The aim of this study is to further our understanding of how the identities of cross-cultural children and young people can be supported and their resources activated. The findings have the potential both to strengthen these children's and young people's resilience and well-being, which would also be of great value to society at large. Psychosocial/cultural interventions and creative projects in cross-cultural settings are potential arenas for this type of cultural health promotion. One example is the multicultural music project Fargespill ('Kaleidoscope').

This article will explore cross-cultural identity development. In a case study of Kaleidoscope, I describe and discuss how these participatory creative activities function, and ask how they may foster the development of constructive cross-cultural identities.

\section{Background: Young Cross-Cultural Lives}

Children and young people with cross-cultural backgrounds constitute a heterogeneous category, and all have their unique life stories with varying degrees of challenges. The common denominator of cross-cultural children and young people is that they "are living or have lived in - or meaningfully interacted with - two or more cultural environments for a significant period of time during childhood" (Pollock \& Van Reken, 2009, p. 31). They share certain common dilemmas and experiences. They will have to relate, with varying degrees of regularity, to different cultural frames of reference, values and expectations. The question whether this contributes to vulnerability or resilience in individual lives, however, can only be answered through empirical studies in specific contexts.

Cross-culturalii children and young people have only occasionally been studied as a single category. Much of the relevant literature uses other terms and categorizations, i.e. immigrant children (Chuang \& Moreno, 2011), minority youth (Cauce, Cruz, Corona, \& Conger, 2011), unaccompanied minor asylum seekers (Dittmann \& Jensen, 2010), and third culture kids (Pollock \& Van Reken, 2009). Kaleidoscope, the project studied here, included participants from all of these different categories. Accordingly, the general term crosscultural children and young people will be applied to the group as a whole, although subcategories will be identified and compared when such nuancing is feasible and fruitful.

Immigrants in general and refugees in particular are statistically speaking vulnerable in terms of both physical and mental health. A review of studies of immigrants' mental health in Norway between 1990 and 2009 concluded that "in the majority of the studies, the immigrant populations, specifically adult immigrants from low and middle income countries, have been found with a higher degree of mental health problems compared to Norwegians and the general population" (Abebe, Lien, \& Hjelde, 2014, p. 60). Similar tendencies have 
been identified among young people. In the "Young in Oslo" survey (Øia, 2007), adolescent girls from immigrant backgrounds reported more mental health problems than Norwegian majority girls.iiiIn addition, Alves et al. (2014, p. 49) recently reported an "overrepresentation of children of immigrants among the emotionally distressed". Several of the health-risk factors involved (less social support, lower family income, more powerlessness) are related to socioeconomic marginalization and inequality rather than cultural factors (Dalgard, Thapa, Hauff, McCubbin, \& Syed, 2006; Ekblad \& Kastrup, 2013).

Migration can provide a new beginning, but is also a psychosocial challenge, especially in cases of forced migration (Sveaass, 2000). According to Lie (2003), refugees carry "a triple burden of trauma, uprooting and settlement". While traumatic experiences and multiple negative life events in the past present a burden to many refugees, their current life situation also often adds to the health challenges they face; especially factors such as acculturative stress, discrimination, poor social support and poor socioeconomic conditions (Abebe et al., 2014). Teodorescu, Heir, Hauff, Wentzel-Larsen, and Lien (2012, p. 316) suggest a "cumulative relationship between pre-resettlement traumas and postresettlement stressors in the mental health of refugees".

Unaccompanied refugee minors are likely to be in a particularly vulnerable position due to migration-related discontinuities and lack of family support during developmentally important stages of their lives. However, our knowledge of the mental health challenges faced by unaccompanied minors and the help they need is still quite limited (Dittmann \& Jensen, 2010).

After migration, refugees are forced to reestablish a sense of meaning and recreate a coherent narrative of their lives (Sveaass, 2000). To varying degrees, this also applies to other immigrants. Identity processes and acculturation become central tasks, with an impact on psychosocial adjustment. Another important factor is how the majority population of the host country receives immigrants (Chryssochoou, 2004). Frequent encounters with prejudice, intolerance and discrimination can add up to a challenge for immigrants' health, identity and experienced opportunity and participation (Prieur, 2004). Many cross-cultural children and young people, especially those from visible minorities, face discrimination and a lack of recognition (Chryssochoou, 2004; Salole, 2013).

Feeling "different" can be a general challenge for the wider category of cross-cultural children and young people, as they have to switch between different cultural expectations and frames of reference, while also transitioning through developmental stages where fitting in can be considered a central task. This can lead to both external and internalized crosspressures and role conflicts (Salole, 2013). Some of the most dramatic examples of the diverging expectations of family versus those of society are cases of honor-related extreme control, including parental pressure, violence and forced marriage (Bredal, 2011; Paulsen, Haugen, Elvegård, Wendelborg, \& Berg, 2011).

Variations in the degrees of psychosocial adjustment between young immigrants of different origins makes it hard to generalize about them as a single group. For instance, one study of young immigrants who had come to Norway from Muslim countries showed that they did not have poorer mental health in general than their majority Norwegian peers (Oppedal and Røysamb, 2007). There are certainly gaps and methodological challenges in this field, and the need for differentiation between groups and individuals with different cross-cultural backgrounds adds further complexity (Chuang \& Moreno, 2011; Salole, 2013). Still, based on the knowledge available, several researchers recommend preventive interventions to strengthen the mental health of immigrants (Abebe et al., 2014; Chuang \& Moreno, 2011), including the cross-cultural "children of migration" in focus here. 
Most of the aforementioned research, however, has been problem focused. Other dimensions and opportunities may open up if a resource-oriented focus is applied. Crosscultural lives may equip children and young people with resources such as language skills, broad and comparative cultural insight, an expanded world view (Salole, 2013), and adaptive skills, as well as equipping them in 'the art of balance' (Prieur, 2004). So-called third culture kids (TCKs) - children who spend part of their childhood in countries and cultures other than their own, due to their parents' international careers (Pollock \& Van Reken, 2009; Salole, 2013) - have more often been studied from a resource-oriented perspective, with an emphasis on how to maximize the benefits of a mobile and transcultural background (cf. Pollock \& Van Reken, 2009). This perspective is perhaps not surprising, as these TCKs often live in relatively privileged circumstances. Recently, however, some scholars and practitioners have suggested and started to explore how some of these TCK resources can benefit other cross-cultural children and young people as well (Pollock \& Van Reken, 2009; Salole, 2013; Selle, Østby, \& Reif, 2001/2015).

Recent findings also suggest cognitive and linguistic benefits related to maintaining multiple cultures and languages (Barac \& Bialystok, 2012; Filippi, Leech, Thomas, Green, \& Dick, 2012; Nguyen \& Benet-Martinez, 2010). Cross-cultural and multilingual people have also been found to score higher on creative tasks (Leung, Maddux, Galinsky, \& Chiu, 2008; Maddux \& Galinsky, 2009). In themselves, these people embody combinations that are something other than the dominant culture and language in a society (Pavlenko \& Blackledge, 2004), reflecting one definition of creativity as "bringing into being something that is both novel and useful" (Leung et al., 2008, p. 170). With their experience of shifting between different frames of references, cross-cultural people are used to living and thinking "outside the box" - continually observing, adapting and finding solutions that fit various situations and challenges (Salole, 2013).

\section{Kaleidoscope - a case study}

Kaleidoscope is a multicultural music project that was started in Bergen in 2004, initially to explore the creativity that may arise from resistance and diversity (Hamre et al., 2011). Kaleidoscope has since been established in several Norwegian towns, with annual performances in many locations. The Kaleidoscope method lets children and young people from different cultural backgrounds share their musical resources (songs, dances, and rhymes) with professional musicians and choreographers. Through these participatory, creative activities, a colorful music/dance performance is created and performed on a local stage. The initiators emphasize that Kaleidoscope is not a "social project", but an art project, and that when participants are viewed as resources, that is what they become (Hamre et al., 2011). 


\section{Theoretical perspectives: Meaning, identity and complexity}

I start from the perspective of social and cultural psychology, understanding human beings as "compulsive meaning-makers" (Valsiner, 2014, p. 8). In other words, we cannot but try to make sense of our worlds, each other and ourselves through cultural interaction.

It is possible to consider cultural meaningfulness, identity development and health as elements within the overarching theoretical framework of salutogenesis (Antonovsky, 1979, 1987 ) - that is, a focus on what strengthens and promotes health, rather on what leads to sickness and ill-health. Social support and inclusion in salutogenetic activities and communities, as well as a range of other factors such as ego identity, coping and creativity, have been found to strengthen salutogenesis (Langeland, 2014). Antonovsky himself emphasized the importance of having a sense of coherence - experiencing comprehensibility, manageability, and meaningfulness in life (Antonovsky, 1987). In other words, as compulsive meaning-makers, we thrive on meaning.

As we also try to make sense of ourselves in meaningful ways, issues of identity arise. Identity is a term widely used in contemporary texts, both academic and popular, to address a range of phenomena from micro level (i.e. self-presentation in social media, body image) to macro level (i.e. identity politics in multicultural societies). Popular as the term is, however, it often goes undefined and its meaning remains rather vague (Prieur, 2004).

In this article I define identity in social psychology terms, as self-interpretation - a "socialcognitive process whereby people give coherence and meaning to their own experiences, including their relations with the physical and social environment" (Simon, 2004, p. 45) involving a varying number of self-aspects. Our self-interpretation is shaped by interaction with our surroundings, and in turn influences our mental processes and behavior.

Simon (2004) presents his Self-Aspect Model of Identity (SAMI) as an attempt at summarizing the social psychology of identity. Relevant research traditions include explorations of the self, especially in North American psychology (self-concept, selfcontinuity, self-esteem, self-realization, self-compassion, etc.), and of social identity, especially in European psychology (group belonging, ingroup vs. outgroups, etc., most prominently known through the Social Identity Theory of Intergroup Relations, see Tajfel \& Turner, 2004). In the SAMI model, these two strands are represented by the dynamics between individual and collective identity. Collective identity is self-interpretation focused on one socially shared self-aspect, while individual identity is based on a complex configuration of self-aspects (Simon, 2004, pp. 49-50). Whether individual or collective identity is most salient will vary situationally and according to the position and context of the person. According to optimal distinctiveness theory (Brewer, 2003), individuals need both belonging and distinctiveness, and thus, an optimal point of distinctiveness on a continuum between personal and social identity is necessary to satisfy this need for a type of identity balance (Gaertner \& Dovidio, 2014).

Thus, identity - while anchored in physical, memory-based, psychological and social continuity - is also inherently dynamic. Our identity will continually be influenced by situations and changes in our circumstances, a phenomenon well-known from migrant experiences (Schuff, 2013; Sveaass, 2000). When we are in a minority, the minority-related self-aspect will often be accentuated by ourselves and others, and collective identification is likely to be activated. This is often experienced as quite limiting. The potential for individual, complex identities is still present, however; we are always more than our most salient identity aspects in any given moment. If people who are normally identified with their minority status are given other arenas, met with other expectations, or given the 
opportunity to play out other self-aspects - then these other aspects can be activated and strengthened, and possibilities open up for a positive and broadly anchored identity development.

One of the reasons why identity issues are important is their impact on health and wellbeing. There is a growing cross-disciplinary body of research that demonstrates the impact of identity (e.g. in relation to membership of, and inclusion in, social groups) on health (Jetten, Haslam, \& Alexander, 2012).

\section{Cross-cultural identities}

It has been argued that cross-cultural children and young people have particular challenges and possibilities when it comes to identity (Salole, 2013). Scholars from several fields, such as social anthropology and sociology, as well as cultural psychology, have tried to describe and understand the identity challenges that may arise from living with multiple cultures (Chryssochoou, 2004; Eriksen, 2010; Nguyen \& Benet-Martinez, 2010; Prieur, 2004). The identity opportunities that have been outlined include:

"Pure" identity: Cross-cultural children and young people are often met with expectations that there is a "final" answer to the question, "But where are you actually from?" This question, however, usually calls for a complex answer in the case of cross-cultural children and young people (Salole, 2013). Nonetheless, they may in some cases choose to cultivate one "pure" identity, often as a reaction to the rejection of more complex identities or to marginalization. In extreme cases this may be linked to radicalization and extremism (Chryssochoou, 2004).

Hyphenated identity: Belonging to both or all cultures a person can trace their origins to, e.g. identifying as Norwegian-Pakistani, Norwegian-Chilean or NorwegianSomali (Eriksen, 2010), in an additive manner.

Hybrid identity: When aspects drawn from various cultural backgrounds and influences merge into a new whole that is different from any of them (Eriksen, 2010). Subcultures among immigrant young people, e.g. gangs, may develop customs and interactional patterns that are neither typically Norwegian nor in accordance with their parents' cultural values and practices (Prieur, 2004).

Flexible identity: This alternative highlights situational variation (Eriksen, 2010); e.g. identifying and behaving as "more Norwegian" at school and "more Somali" at home. Norwegian-Chilean children may participate in typical Norwegian after-school activities and go to bed early on weekdays, while staying up much later than their Norwegian peers on a Saturday night for an intergenerational 'fiesta'.

Multicultural identity: Exposure to and internalization of two or more cultures; and "having strong attachments with and loyalties toward these different cultures" (Nguyen \& Benet-Martinez, 2010, p. 4)

Integrated intercultural identity: This pattern of identification will allow the crosscultural person to choose to be complex and multifaceted also in terms of cultural identity - to be "all of the above, and more" (Salole, 2013). 
Several scholars, using varying and often overlapping terms, have argued that for crosscultural individuals, complex forms of identity (hyphenated, hybrid, flexible, multicultural, integrated) are related to better mental health and psychosocial adaptation than a reductive, singular cultural identification (Berry, Phinney, Sam, \& Vedder, 2006; Phinney, Horenczyk, Liebkind, \& Vedder, 2001; Sam \& Oppedal, 2003). Immigrant young people who identify with and master both their culture of origin as well as the host culture (with an integration profile, in acculturation terms), have been found to have better psychological and sociocultural adaptation outcomes. Accordingly, immigrant young people "should be encouraged to retain both a sense of their own heritage cultural identity, while establishing close ties with the larger national society" (Berry et al., 2006, p. 303).

Whether or not cross-cultural children and young people get the opportunity to balance, adapt and negotiate their different self-aspects, may therefore be a key issue in their development of a positive cross-cultural identity. Cross-cultural children and young people may experience cultural marginality in the sense that they "construe their identities at the margins of two or more cultures and central to none" (M. J. Bennett, 2004, p. 8). Bennett (1993) suggests that this marginality may be either encapsulated or constructive. If a person is not allowed flexibility, and is, e.g. forced into a "pure" identity by family or society, an encapsulated marginality might be the outcome. This is experienced as alienation and inner conflict. On the other hand, if these young cross-cultural individuals find strategies for integrating their intercultural experiences, in exploratory and stimulating environments, they may experience a constructive marginality "in which movements in and out of cultures are a necessary and positive part of one's identity" (M. J. Bennett, 2004, p. 8 ). The development of flexible, complex identities and constructive marginality seems to depend on acknowledgment of cross-cultural experiences, and the activation of skills and values from one's different cultures (Oppedal et al., 2008; Salole, 2013; Schandy, 2013).

Based on the identity theories presented above, what does it mean to support cross-cultural identity development? I will here operationalize this concept as allowing, increasing and acknowledging identity complexity. When it comes to identity, there is arguably strength in complexity as well as in flexibility. High self-complexity has been found to be a resilience factor in times of crisis (Simon, 2004). A strong and dynamic ego identity has also been linked to salutogenesis (Langeland, 2014) and to resilience (Borge, 2007).

Simon's (2004) self-aspect model implies that individual identity is characterized by the salience of higher complexity, while collective identity is more one-dimensional or focused on a single, shared self-aspect. Collective identity may provide social belonging and be necessary to make collective action possible. On the other hand, individual identity may counteract intergroup conflict and be understood as linked to values such as freedom and flexibility. In contemporary Western societies, individuality and individual identity are cultural and ideological ideals (Simon, 2004).

However, neither of these two forms of identity are more or less "good", healthy or essential to the person than the other, according to Simon - they are rather two sides of the same coin, more accurately understood as engaged in mutual interplay than as opponents (Simon, 2004). In the case of cross-cultural children and young people, who are often positioned as members of minorities, the tendency will typically be that their complex individual identities are often not activated and acknowledged. Thus, a fruitful starting point to support constructive cross-cultural identity development is to allow and nurture a flexible interplay between individual and collective identities - and the integration of a range of selfaspects and backgrounds into an acknowledged, complex identity. 


\section{Methods and material}

Participant observation was conducted in Kaleidoscope in a Norwegian town from February to November 2014. I attended rehearsals at least biweekly throughout the period, and stopped by daily during the last intense week leading up to the performances in October. Through participant observation, identity was explored in terms of identity negotiations observed during interaction. Close to 100 children and young people participated in the project. Their ages ranged from 7 to 22, with some participating for shorter periods of time but most for the entire period. The sample thus consisted of participants in Kaleidoscope in the first year of the project (2014) in the specific location in question. The children were recruited from two local schools in culturally mixed neighborhoods. The young people were invited mainly through the municipally run group for unaccompanied refugee minors, but also through the local hospital's child and adolescent mental health services and the local municipal cultural school (kulturskolen). Most of the participants had a cross-cultural background, as immigrants or children of immigrants, while there were also some children and young people of Norwegian origin. The intention is to stage annual performances, with some new participants joining the project each fall. In addition to the young participants, the fieldwork involved the three music professionals who led the project (a singer/voice teacher, a musician and a choreographer, respectively), and at times, some other teachers and social workers. The participants soon treated the observer as a type of assistant/teacher during rehearsals and performances.

The research materials also include written sources that have become relevant during the course of the fieldwork, in particular the book "Kaleidoscope", which presents the project, (Hamre et al., 2011) and related web pages (Fargespill, 2015; KildenDialog, 2014). This triangulation implies that the materials as a whole draw on the perspectives of participants and of project leaders as well as on the interaction between them, as observed and interpreted by the researcher.

The field notes and other materials were subjected to a qualitative content analysis, involving coding, categorizing and comparisons (Flick, 2008) in a process of thematic coding (Braun \& Clarke, 2006). Guided by my research question concerning identity development, I looked for findings that could shed light on the self-interpretations of participants and the spaces that were opened up for the development of such identity processes. By comparing and interpreting my observations in the light of the theories outlined above, I identified three main categories - resources, vulnerability and creativity - and the analysis was subsequently organized under these headings.

\section{Ethical considerations}

The project has been approved by the Privacy Ombudsman for Research at Norwegian Social Science Data Services (NSD), and follows their guidelines for informed consent (from participants, and the parents/guardians of minors), confidentiality and design. The ethical baseline of the project was respect and care for the children and young people that participated, with the explicit intention of ensuring their genuine participation and their voices being heard (cf. Nelson \& Prilleltensky, 2010). The achievement of these goals was promoted through a continuous dialogue with the participants and others involved (leaders, teachers, social workers, as well as the author's research networks). Particular attention has been paid to communicating in linguistically and culturally sensitive ways throughout the research process. For instance, the letters requesting informed consent contained a note in several languages inviting recipients to request a translation or more information, and were supplemented by oral communication. I have also endeavored to present the participants and the groups and ethnicities they are associated with in non-stereotypical ways. This is 
perhaps particularly important in research involving members of ethnic minorities (Ingierd \& Fossheim, 2014).

\section{Findings and analysis}

The creative activities that take place within the Kaleidoscope project relate to identity right from the start, in the sense that a basic premise for the Kaleidoscope concept is that the cultural and ethnic identities of the participants are diverse - this is "all the world on one stage" (Fargespill, 2015). This basic premise is expressed in Kaleidoscope's objective, which is "to create an arena for mutually enriching cultural encounters where different identities and cultural/artistic competency are brought to the fore and appreciated" (KildenDialog, 2014, p. 1, my translation and emphasis added).

The young participants sense the project's implicit emphasis on their otherness, as became apparent during the first session in one of the schools. Having gathered the children around and presented themselves, one of the leaders asked: "Do you know what we want you to do now?" A young pupil of African origin raised his hand, and when she pointed to him, replied loud and clear: "You want us to do 'foreigner stuff"' (In the original Norwegian: 'sånne utlendingsting'.) This caused some laughter among both the children and the adults. The same leader then - with a smile - proceeded to explain how the project leaders believed that what the children could bring to this project, based on their backgrounds, the songs and dances and games they knew from different parts of the world, was of great value and would help create a unique performance.

This exchange can be understood in several ways: the focus on the children's origins could on the one hand be seen as expressing stereotyping and exotification, as was elegantly expressed by the young participant who realized that in this context he was considered interesting as a foreigner. On the other hand, it could be seen as a celebration of diversity, a point made explicitly by the Kaleidoscope leaders both in writing (e.g. Hamre et al., 2011; KildenDialog, 2014) and in conversation. In this sense, the exchange also provided a perhaps rare opportunity for the cross-cultural participants to express and be acknowledged for their minority or non-Norwegian self-aspects. In the process, the children and young people could "see each other more clearly" for who they were, as one of the leaders put it in the course of a field conversation about the exchange.

In this exchange, there was a clear emphasis by the project leaders on the participants' status as resources in themselves. In addition, there was a subtext concerning the vulnerability of potentially stereotyped minorities, and explicit expectations of creativity to come. In other words, the cross-cultural identities of the participants were simultaneously linked to the dimensions of resources, vulnerability and creativity. These three phenomena often appear together, but will be presented separately for the purpose of the following analysis.. 


\section{Resources}

The initiators of Kaleidoscope emphasize their resource-oriented focus when describing the project:

Kaleidoscope is exclusively resource-oriented. We who created the concept are as dependent on the performers as they are on us. We perform with these children and youngsters because no one else is capable of doing what they do.

(Hamre et al., 2011, p. 12)

The creative activities take place within a framework that features several markers of high quality. Each Kaleidoscope project is led by professional musicians and choreographers (rather than by therapists or other "helpers"), and is performed in large, prestigious cultural institutions.iv As a result, the participants' status as important resources and valuable contributors is not only recognized verbally, but also institutionally and professionally.

The initiators of Kaleidoscope express their belief in the identity-strengthening potential of this approach by stating that the participants, when regarded as assets,

can establish a new image of themselves rooted in their experience of mastering something, in the feeling of being valuable to others rather than just being victims. If you are perceived as a resource, you become a resource.

(Hamre et al., 2011, p. 12)

Arguably, this process of being seen as, and beginning to see oneself as, a resource has been observed in the case of several participants during the time from the start of the project until the first performance. A teenage girl, who would barely say her name out loud at the first rehearsal, took center stage at the concert hall nine months later, in front of hundreds of spectators, and sang a solo verse. A young man, who had arrived in Norway as an unaccompanied refugee minor and who now works hard to support his distant family financially, and who rarely made it to rehearsals on time, smilingly performed spectacular dances during the performance. Children who had often interrupted the rehearsals at school surprised their teacher by staying fully focused for the entire hour of the performance. Their teacher called it "a miracle".

How were these processes facilitated? The project leaders worked intentionally to establish trust and a safe, supportive space through the application of a participatory method. During the early rehearsals, the leaders took time to learn participants' names; to sing birthday songs in several languages simultaneously on participants' birthdays; to play and sing simple songs together; and to do simple physical warm-up activities in a circle. Little by little, more and more participants dared to share some of their own songs and dances in the group: a lullaby here, a clapping game there. Such expressions, especially traditional folk music and dance, were received warmly by the leaders, who referred to them as "treasures". Most of the children and young people seemed to become increasingly comfortable in the rehearsal setting, and to enjoy getting to know the leaders, as well as each other. After a few months, several participants had started to hug the leaders when they met or parted.

The relationships and sense of community that developed during the first year of the project can be seen as resources in their own right, with the potential to contribute to positive self- 
interpretations and the strengthening of interdependent identities. As the group worked towards a common goal, there was a growing sense of togetherness, with friendships developing and participants giving each other mutual support. When the time of the performance finally arrived, one of the young people exclaimed emotionally to her relatively new friends "All of you have to continue in Kaleidoscope!" - meaning that she wanted them to stay with the project for the next performance, planned for the following year. The three different groups of participants (who came, respectively, from two schools and a youth group) had mostly rehearsed separately throughout the year. As the date of the performance neared, however, the participants came together for rehearsals during the intense period leading up to the performance. During this period, there was an increasing tendency for the participants to bond across internal group boundaries as well. Younger children gave older participants admiring looks, and the older participants joked with and cared for the younger ones, often commenting on their cuteness as they sang and danced. The "oneness" of the group was also embodied in musical and choreographic synchronization during the performance, such as when all the participants shouted "Fargespill!" together, lifting their voices as the "Kaleidoscope community".

In this emerging Kaleidoscope community, cultural and ethnic differences were routinely acknowledged and valued. This occurred most explicitly through songs and dances, but also more generally through discussions of cultures of origin (or for some, their parents' cultures of origin). The older participants shared stories about cultural peculiarities and intercultural encounters, and these were received with laughter and understanding. Some of the ethnic Norwegian participants described how they had moved - within Norway - several times during their childhoods, and compared their experiences with those of participants from immigrant backgrounds: "It's different, of course, but I also find it hard to answer when people ask where exactly I'm from," said one girl during a rehearsal break. Participants of all ages admired each other's "ethnic" costumes. Kaleidoscope costumes are always the participants' own clothes, preferably national costumes or some other clothing that expresses their own or their parents' origins. Alternatively, the participants may wear "something nice in bright colors".

The project leaders also specifically recognized the participants' unique contributions both during rehearsals and in pre-performance pep talks. "We need what every one of you brings to the group," the leaders would say. The leaders were also consistent in responding warmly and appreciatively when a participant shared a song or made a suggestion. On the day of the performance, one leader told the performers: "Kaleidoscope would not have become what it is today without each and every one of you. And what you have to give really moved people today. I am so immensely proud of all of you."

Generally the participants also seemed very excited and proud at the time of the performance, smiling, cheering and congratulating each other. Some said that their parents were happy to see them take part, with some parents even being moved to tears by songs from their home countries. A few of the participants also expressed gratitude specifically for the opportunity to express the minority aspects of their cultural identities. "I didn't think I would get to express the Sámi part of me here in southern Norway, but here I get the opportunity. I really enjoy it," one girl said.

In addition to recognition from the project leaders and each other, the participants were acknowledged by their families, friends, teachers, other artists and directors, as well as the media. The project and a number of participants were portrayed in a long feature article in the regional newspaper, and this was something that the participants seemed very excited about. The performance in October attracted a full house. When the group reconvened almost a month later, the participants shared the post-performance feedback they had 
received. One participant had heard that the artistic director of the whole arts complex had loved it. Smiling broadly, she also told the others about an episode in which she herself had been a recognized celebrity: "This little boy came up to me at a bus stop, and told me he had seen me at Kaleidoscope!"

\section{Vulnerability}

Cross-cultural children and young people are often vulnerable in that they are likely to feel different and be seen as minorities. In particular, they are often categorized by others in reductionist ways that do not do justice to the complexity of their identities. During the Kaleidoscope process, identity negotiations took place in ways that expressed a certain level of sensitivity to stereotypes and simplification. Many of the children recruited from the two schools had been born in Norway and had one or two foreign-born parents. During the early rehearsals at one of the schools, the project leaders sometimes asked children "Which country are you from again?" Several times, some of the children would then reply with some determination: "I am Norwegian! My parents are from Eritrea," or "my mother is from Thailand, I was born here," and so on. After a few similar exchanges, the leaders adjusted their choice of words with these children in particular, addressing the issue of origin in a more nuanced way (e.g., "Could you bring some clothes from the country that your father or mother is from next week?"). In other words, as an outcome of these negotiations, identity complexity was increasingly recognized and verbalized as the project progressed and the participants and leaders got to know each other.

At first sight, vulnerability is rarely an explicit focus in Kaleidoscope, as the leaders practice the strongly resource-oriented approach described above, repeatedly emphasizing the participants' strengths and positive contributions. In their book, Kaleidoscope's initiators, who work mainly with recently arrived refugee children and young people, explain

We focus on their resources, not their tragedies. It's very important for people who come here and have maybe experienced difficult things to given an alternative to being a victim. (...) Having said that, we come pretty close to our performers. So it can feel natural for them that they tell us about their backgrounds, and then it's important that they do. For us, too. Their stories give our performances perspectives they wouldn't otherwise have had.

(Hamre et al., 2011, p. 34)

Thus, even though the participants' vulnerabilities and troubling experiences are not put center stage, this context makes the positive, colorful musical performances even more remarkable.

The participant group is also vulnerable in some very practical ways, and some participants need extensive follow-up by the project leaders. For various reasons, it has been challenging for some participants who are not rehearsing within a school context to show up consistently and on time for rehearsals. Some have little or no experience of this type of event, and are not used to attending a regular schedule of cultural/musical rehearsals. Some have work- and/or family-related responsibilities, or skip rehearsals during exam periods. Several participants dropped out of the project before the performance. In some cases this was because they had moved and left the school that was involved in Kaleidoscope (an inner-city school with high student turnover). Others dropped out due to cooperation problems with their parents. And most dramatically, one of the young people was suddenly deported with his family to Afghanistan since their asylum application had not 
been granted. This turn of events was received with shock and sadness in the youth group, and also shook the project leaders.

Most of the participants, however, not only stayed with the project until the performance, but were also intent on continuing for the next year. There was obviously a good deal of variation between the experiences and involvement of these participants. For example, two girls from the same country of origin suggested the same song, but only one was chosen to teach the others and be the lead singer. Another participant asked the researcher-observer on several occasions, right up until the week of the performance, if he could be lead the singer for a song that he had known since he was a little boy. Another lead singer had already been chosen, however. It is likely that some participants receive more attention and recognition, and experience the mastering of new skills that may in turn strengthen their self-confidence and several aspects of their identity, while others feel somewhat left out. The project leaders try to solve this dilemma by emphasizing how all participants are equally important, whether they are singing along from the back of the stage or dancing brilliant solos.

Issues of ownership over the songs also came up, although not often. A girl, who had spent a lot of time with the participant group from her school rehearsing "their" song, mentioned to the researcher that she thought it strange that two professional singers were going to sing along with them during the performance. These professional singers had only rehearsed with the children during the final week before the opening performance. The girl told me, "They sing it wrong. They don't know how to pronounce the words properly. My class, we've practiced this song for so long already, we know it well." She and a friend had been the experts for this song, using their knowledge of the language and melody to teach their fellow pupils. Now the involvement of professionals, with the intention of enhancing the musical quality of the act, seemed to have estranged the participant somewhat from her own song. The leaders of Kaleidoscope generally argue that such adjustments are necessary in order to ensure uniformly high quality, which ultimately will benefit all the participants in allowing them to experience participation in an outstanding and spectacular event (Hamre et al., 2011).

\section{Creativity}

Kaleidoscope aspires explicitly to high-quality creativity. The projects are designed to be creative from the outset, leading to new and original performances. A key element of the creative process is the frame-shifting so typical of cross-cultural individuals, and here one might say that it also takes place at a group level. While assembling the musical material, the project leaders and participants move between different cultural traditions, scales and rhythms. These become creative expressions in that they are unique and new in the setting of a Norwegian stage, and new in the ways they are combined and rearranged.

The first few months of the project were focused around getting to know each other and building trust - commonly recognized as fertile soil for creativity - so that the children and young people would feel safe enough to share songs, games and dances with the leaders and the rest of the group. Simple, creative exercises in a circle ("say your name with a movement, and the rest of us will repeat it") prepared the ground for more expressive sharing later on. The 'Kaleidoscope rules' (cf. Hamre et al., 2011, p. 59), which include respecting each other and being positive and focused during rehearsals, were established in the group early on. The leaders emphasized that "we listen quietly to each other" and never laugh at each other's contributions. The leaders also frequently reminded the participants that "nothing is wrong here" and that all contributions were valuable. 
With regard to the musical material for the performance, however, the project leaders mainly worked with traditional folk music and dances. During rehearsals, they might ask for "something your parents or grandparents would sing to you when you were little" or "how you would dance at a wedding in Afghanistan". When participants shared songs by individual contemporary artists, these were also listened to but rarely considered 'performance material'. Kaleidoscope's initiators consider folk music to be a "defining element" of the project, arguing that these old songs have survived through the centuries because "they speak to us all. Some of them survive the test of time - it has to do with quality" (Hamre et al., 2011, p. 35). The researcher/observer also noted that the project leaders spoke enthusiastically about how well elements of folk music from different parts of the world can be combined. This is due to the fact that they share the same basic scales (most often a pentatonic scale).

Folk music and dances were also seen as closely linked to identity, perhaps in a more profound way than newer musical expressions. The project leaders commented on how beautiful it was to see the young participants express themselves with these songs, and leaders and participants alike seemed to share excitement about the diversity of distinctive musical and cultural traditions. While the children and young people also expressed pride in sharing their folk music at times, they appeared not to differentiate as much between traditional and contemporary music when it came to their involvement and identification. Songs they knew the words of and presented as "theirs" were just as often newer songs. Nonetheless, there were several episodes when participants told the project leaders how their parents or other older friends or relatives with the same ethnic origin had been very moved by hearing a traditional tune from home.

Some of the material was composed by the participants themselves, including a rap in Farsi, and a Sámi joik. The composers/performers expressed great satisfaction in expressing themselves in such a personal way.

Most of the acts included in the performances involved several songs and/or dance moves from different cultures: lullabies from Somalia, Uruguay, Norway, and Sweden; or songs about animals from Chile, Estonia and Norway. The 10th anniversary performance in Bergen ended with a Palestinian and an Israeli song combined. This mix of different cultural expressions is central to Kaleidoscope's creative processes, yet can sometimes be challenging. During one rehearsal, a group of participants was asked to teach the others an Afghan dance they had demonstrated earlier. Meanwhile, the project leaders switched on music from the Middle East. After trying for a short while to fit familiar steps to new music, one of the dancers stopped and exclaimed: "I can't do this! It just all becomes a 'salad'!" One of the Kaleidoscope leaders was quick with a good-humored response: "Well, salad is healthy, right?" The participants smilingly continued trying to match their steps to the music.

Several months later, the same participant explained that the mix he had found confusing at first now made sense: "I thought it was impossible, but it turned out really cool". This is an example of how the participants in Kaleidoscope grow accustomed to cultural complexity as the creative processes unfold. There were also examples of participants whose parents came from different countries sharing songs or dances from both of them; embodying their cross-cultural life stories through creative interaction.

While there is an emphasis on diversity and the creative combination of differences, through the Kaleidoscope process the participants also develop a distinctive sense of community, togetherness and equality. Everyone is allowed to contribute on an equal footing from the outset; friendships are formed; leaders and participants hug and laugh together; and by the time of the performances, the participants are telling each other "never quit Kaleidoscope". 
This reflects the claim made by the initiators of Kaleidoscope that "it's the combination of sameness and difference that makes our Kaleidoscope encounters so rich." (Hamre et al., 2011 , p. 52). Both sameness and difference are embodied as all the participants sing and dance together, while the ways in which they move and sing express different physical ways of being in the world (cf. Bourdieu, 1986 on habitus including embodied cultural capital), shaped by distinctive traditions and experiences. Among these experiences, the ongoing Kaleidoscope experience might in itself influence their ways of being in the world in the present and future.

\section{Discussion: Setting the stage for identity development?}

Kaleidoscope is about identity - about expressing who we are. (...) In Kaleidoscope we see people who are just like you and me, in spite of differing colour, ethnicity, social class and life stories. We see this because the performers get the chance to show their humanity.

(Hamre et al., 2011, pp. 56-57)

This 'Kaleidoscope philosophy' emphasizes the participants' common humanity, as well as more specific commonalities: their shared creative project towards a common goal; mutual respect; simply having fun together. From the perspective of social identity theory, this could be understood as forming a common ingroup identity (Gaertner \& Dovidio, 2014) within Kaleidoscope. Recategorization from a set of different group identifications or ingroup/outgroups ("Norwegians", "Afghans", "Chileans", etc.) to one larger, common ingroup ("Kaleidoscope participants"/"young creative people in Norway") may reduce bias and promote group integration. This was observed in practice as the forming of friendships and group cohesion throughout the process.

At the same time, while the participants are "all the same", differences are clearly acknowledged and valued, in line with optimal distinctiveness theory. Another analytical perspective on this dialectic is to apply both a descriptive and a dynamic concept of culture: culture as something the participants have (descriptive and referring to origin(s) and cultural differences), and culture as something they $d o$, together, understood as a dynamic communicative process in flux (Dahl, 2013; Schuff, 2014) - of which Kaleidoscope may be an almost archetypal example. Even though the descriptive concept of culture has been subjected to particular criticism, e.g. for tending towards stereotyping, Dahl argues that we need both of these concepts of culture if we are to be optimally equipped for intercultural communication, and to grasp cultural differences, as well as cultural change and flexibility. I would also argue that it is useful to keep both concepts in mind in order to understand cultural identities as something simultaneously rooted and dynamic. This approach aligns well with the different complex cross-cultural identities outlined above, particularly hybrid, flexible and integrated intercultural identities.

In Kaleidoscope, these 'rooted dynamics' are expressed in practice when the participants sing their own songs, from their own or their parents' cultures of origin, and also experience them being mixed with expressions from other cultures, combining with other elements into a new whole (and possibly, a hybrid identity): this is culture in the making. In Simon's (2004) terms, the participants get to express multiple self-aspects in this context, linked to all of the cultural, social and individual dimensions that make up who they are. Many participants also seem to learn to enjoy the cross-cultural "salad", an aesthetic of diversity, in a new way through personal experience. 
I have previously argued, based on an earlier study of a multicultural gospel choir (Schuff, 2014), that the experience of cultural participation - that is, the opportunity to contribute and be acknowledged as a valuable participant in cultural interaction - may contribute to well-being and health. This current study appears to indicate that this type of participation may also be central to identity expression and the development of a positive, complex identity for cross-cultural children and young people.

Kaleidoscope is based on a participatory method which has much in common with empowerment perspectives. Such perspectives typically emphasize increased participation in the processes that influence one's own situation and well-being, and moving from victimhood towards becoming a resource oneself (Nelson \& Prilleltensky, 2010; Rolvsjord, 2004). This is also reflected in the Kaleidoscope leadership's axiom: "If you are perceived as a resource, you become a resource." (Hamre et al., 2011, p. 12) This statement, intentionally or not, mirrors the classic Thomas theorem of sociology; "If men define situations as real, they are real in their consequences" (Thomas \& Thomas, 1928, p. 572). Identity theories within social psychology also commonly emphasize the power of perceptions, expectations and interactions in shaping identity. Given other expectations and room for expressing other self-aspects, one's identity can develop and grow in complexity (Simon, 2004).

In Kaleidoscope, this potential increased complexity can be analyzed as interactions between a series of apparent contradictions: resources/vulnerability; origin/contemporary community; traditions/new creative expressions and mixes; and, as already mentioned, sameness/difference. Contradictions that are otherwise often a challenge become a resource in this particular setting. Flexible and integrated intercultural identity strategies allow these apparent contradictions to exist in participants' self-interpretations.

It seems that these dynamics of complexity may also provide fertile ground for creativity, i.e. the juxtaposition of vulnerability and resources, of old and new expressions. Logically speaking, if creativity has to do with the production of something new or original, expressions or content carried over from one culture to another will then often be new and original in that new context. Anheier and Isar argue that diasporas and other settings in which different cultures and people meet and "struggle for space and speak across cultural languages are some of the most creative sites in the contemporary world" (Anheier \& Isar, 2010 , p. xii). Thus, a cross-cultural arena such as Kaleidoscope may be a good place to look for creativity as both an artistic resource and a health resource.

Creativity has been considered a protective factor or process in resilience groups for refugee children (Waaktaar \& Christie 2000), and has also been considered a health resource within salutogenic research and theory (Langeland, 2014), and in rehabilitation (Batt-Rawden \& Tellnes, 2005). The experiences depicted in these studies are in some ways similar to what happens in Kaleidoscope, although Kaleidoscope may have a particularly explicit resource/quality focus, due to its position in cultural institutions that produce performances on a professional stage.

In Kaleidoscope, the content of the interaction is based on creative arts and multimodal expressions. Music, dance and other embodied modalities can be particularly meaningful when it comes to exploring and expressing cross-cultural experiences, which are often embodied, unconscious and may evade verbalization (Salole \& Van der Weele, 2010). Experiences from art therapy with unaccompanied refugee minors have been similarly positive (Schriever, 2011).

One point to keep in mind is that the positive term creativity, if used uncritically, may disguise how "in cultural collision of this kind, questions of identity, recognition and power 
are always 'in play'." (Anheier \& Isar, 2010, p. xii). Although the identity negotiations in Kaleidoscope take place in the friendliest of atmospheres, there is nonetheless a context of power differences that requires the project leaders to exercise responsibility and empathy. Thus it has been reassuring to see that the leaders are often understanding of the participants' reactions and sensitivities, e.g. to stereotyping, and adjust their categorizations of the participants accordingly.

\section{Concluding reflections}

Kaleidoscope is a colorful celebration of diversity that has generated considerable excitement. It celebrates the cultural identities and backgrounds of its participants, who have an opportunity to express aspects of themselves for which they rarely find appreciation in Norwegian mainstream society. It may seem safe to conclude that participation in Kaleidoscope strengthens the participants' identity development.

Even so, this is not the full story. Emphasizing one self-aspect, i.e. that relating to the participants' minority backgrounds, may actually limit identity development in the sense that it ties people to that one self-aspect, and pushes their individual complexity - their full range of self-aspects - into the background. This touches upon issues of stereotyping and power differences, with regard to definitions, control and ownership, throughout the process. This implies that a great deal of responsibility rests on the professionals and other adults involved. Cultural and interpersonal sensitivity, as well as openness to complexity, will be key factors for successfully handling these relational and identity processes in a fruitful and ethically sound manner.

In this case study, the interactions between the project leaders and participants included many examples of mutual sensitivity and openness. As the project developed, the danger of stereotyping was partially erased by an opposite dynamic: the participants showed each other more self-aspects as they got to know each other, sang each other's songs, took part in what became new musical/dance expressions, and formed friendships in a creative community that also allowed them to bring something new to the table - under careful professional guidance. This allowed space for identity complexity to play out, both in relation to the participants' origins and their current participation in culture in construction here in Norwegian society.

Accordingly, Kaleidoscope at its best sets the stage for a flexible and playful performance of identity, and this may be one path towards appreciated and integrated intercultural identities. 


\section{References}

Abebe, D. S., Lien, L., \& Hjelde, K. H. (2014). What We Know and Don't Know About Mental Health Problems Among Immigrants in Norway. Journal of Immigrant and Minority Health, 16(1), 60-67. http://dx.doi.org/10.1007/s10903-012-9745-9

Alves, D. E., Corliss, H. L., Røysamb, E., Zachrisson, H. D., Oppedal, B., \& Gustavson, K. (2014). Immigrant Preadolescents and Risk of Emotional Distress. Scandinavian Journal of Child and Adolescent Psychiatry and Psychology, 2(1):41-51. http://hdl.handle.net/11250/219585

Anheier, H. K., \& Isar, Y. R. (2010). Cultures and globalization: cultural expression, creativity and innovation: Sage.

Antonovsky, A. (1979). Health, Stress and Coping. San Francisco: Jossey-Bass.

Antonovsky, A. (1987). Unraveling The Mystery of Health. San Francisco: Jossey-Bass.

Barac, R., \& Bialystok, E. (2012). Bilingual effects on cognitive and linguistic development: Role of language, cultural background, and education. Child Development, 83(2), 413422. http://dx.doi.org/10.1111/j.1467-8624.2011.01707.x

Batt-Rawden, K. B., \& Tellnes, G. (2005). Nature-culture-health activities as a method of rehabilitation: an evaluation of participants' health, quality of life and function. International Journal of Rehabilitation Research, 28(2), 175-180. http://dx.doi.org/10.1097/00004356-200506000-00013

Bennett, J. M. (1993). Cultural marginality: Identity issues in intercultural training. Education for the intercultural experience, 2, 109-135.

Bennett, M. J. (2004). Becoming interculturally competent. In J. Wurzel (Ed.), Toward multiculturalism: A reader in multicultural education (Vol. 2, pp. 62-77). Newton, MA: Intercultural Resource Corporation.

Berry, J. W., Phinney, J. S., Sam, D. L., \& Vedder, P. (2006). Immigrant Youth: Acculturation, Identity, and Adaptation. Applied Psychology, 55(3), 303-332. http://dx.doi.org/10.1111/j.1464-0597.2006.00256.x

Borge, A. I. H. (2007). Resiliens i praksis: teori og empiri i et norsk perspektiv: Gyldendal Akademisk.

Bourdieu, P. (1986). The forms of capital In I. Szeman \& T. Kaposy (Eds.), Cultural theory: An anthology (2011 ed., pp. 81-93).

Braun, V., \& Clarke, V. (2006). Using thematic analysis in psychology. Qualitative research in psychology, 3(2), 77-101. http://dx.doi.org/10.1191/1478088706qp063oa

Bredal, A. (2011). Mellom makt og avmakt. Om unge menn, tvangsekteskap, vold og kontroll. Oslo: Institutt for samfunnsforskning.

Brewer, M. B. (2003). Optimal distinctiveness, social identity, and the self. Handbook of self and identity, 480-491.

Cauce, A., Cruz, R., Corona, M., \& Conger, R. (2011). The Face of the Future: Risk and Resilience in Minority Youth. In G. Carlo, L. J. Crockett \& M. A. Carranza (Eds.), Health Disparities in Youth and Families (Vol. 57, pp. 13-32): Springer New York. http://dx.doi.org/10.1007/978-1-4419-7092-3_2

Chryssochoou, X. (2004). Cultural Diversity. Its Social Psychology. Oxford/Malden/Carlton: Blackwell Publishing.

Chuang, S. S., \& Moreno, R. P. (Eds.). (2011). Immigrant Children. Change, Adaptation, and Cultural Transformation. Lanham: Lexington Books.

Dahl, $\varnothing$. (2013). Møter mellom mennesker. Innføring i interkulturell kommunikasjon. Oslo: Gyldendal akademisk. 
Dalgard, O. S., Thapa, S. B., Hauff, E., McCubbin, M., \& Syed, H. R. (2006). Immigration, lack of control and psychological distress: Findings from the Oslo Health Study. Scandinavian Journal of Psychology, (47), 551-558. http://dx.doi.org/10.1111/j.1467-9450.2006.00546.x

Dittmann, I., \& Jensen, T. K. (2010). Enslige mindreårige flyktningers psykiske helse - en litteraturstudie. Tidsskrift for Norsk Psykologforening, 47(9), 812-817.

Ekblad, S., \& Kastrup, M. C. (2013). Current research in transcultural psychiatry in the Nordic countries. Transcultural psychiatry, 50(6), 841-857.

http://dx.doi.org/10.1177/1363461513511181

Eriksen, T. H. (2010). Samfunn. Oslo: Universitetsforlaget.

Fargespill. (2015). Fargespill. Retrieved 10.02., 2015, from http://www.fargespill.no

Filippi, R., Leech, R., Thomas, M. S., Green, D. W., \& Dick, F. (2012). A bilingual advantage in controlling language interference during sentence comprehension. Bilingualism: Language and Cognition, 15(04), 858-872. http://dx.doi.org/10.1017/S1366728911000708

Flick, U. (2008). Designing qualitative research: Los Angeles/London/New Delhi: Sage.

Gaertner, S. L., \& Dovidio, J. F. (2014). Reducing intergroup bias: The common ingroup identity model: Psychology Press.

Hamre, O., Saue, S., Bræin, I., Fauske, E., Lyslo, Ø., \& Dillan, G. (2011). Kaleidoscope. Bergen: Fargespill.

Ingierd, H., \& Fossheim, H. J. (2014, 10.10.2014). Etniske grupper. Retrieved 18.12., 2014, from

http://etikkom.no/no/FBIB/Temaer/Forskning-pa-bestemte-grupper/Etniske-grupper/

Jetten, J., Haslam, C., \& Alexander, S. H. (2012). The social cure: Identity, health and well-being: Psychology Press.

KildenDialog. (2014). Fargespill Kristiansand. Retrieved 10.02., 2015, from http://www.kilden.com/fargespill

Langeland, E. (2014). Salutogenese og psykiske helseproblemer - en kunnskapsoppsummering (Vol. 1). Bergen: Nasjonalt kompetansesenter for psykisk helsearbeid (NAPHA).

Leung, A. K.-y., Maddux, W. W., Galinsky, A. D., \& Chiu, C.-y. (2008). Multicultural experience enhances creativity: the when and how. American Psychologist, 63(3), 169. http://dx.doi.org/10.1037/0003-066X.63.3.169

Lie, B. (2003). The triple burden of trauma, uprooting and settlement: a non-clinical longitudinal study of health and psychosocial functioning of refugees in Norway. (PhD, Dr. med.), University of Oslo, Oslo.

Maddux, W. W., \& Galinsky, A. D. (2009). Cultural borders and mental barriers: the relationship between living abroad and creativity. Journal of personality and social psychology, 96(5), 1047. http://dx.doi.org/10.1037/a0014861

Nelson, G., \& Prilleltensky, I. (2010). Community psychology: in pursuit of liberation and well-being. Basingstoke: Palgrave Macmillan.

Nguyen, A.-M. D., \& Benet-Martinez, V. (2010). Multicultural identity: What it is and why it matters. The psychology of social and cultural diversity, 87-114.

http://dx.doi.org/10.1002/9781444325447.ch5

Oppedal, B., Azam, G. E., Dalsøren, S. B., Hirsch, S. M., Jensen, L., Kiamanesh, P., Seglem, K. B. (2008). Psykososial tilpasning og psykiske problemer blant barn innvandrerfamilier. Rapport 2008: 14 [Psychosocial adjustment and mental health problems among children in immigrant families. Report 2008: 14. 
Paulsen, V., Haugen, G. M. D., Elvegård, K., Wendelborg, C., \& Berg, B. (2011). Æresrelatert ekstrem kontroll - dilemmaer og utfordringer Mangfold og inkludering (pp. 102). Trondheim: NTNU Samfunnsforskning.

Pavlenko, A., \& Blackledge, A. (2004). Negotiation of identities in multilingual contexts (Vol. 45): Multilingual Matters.

Phinney, J. S., Horenczyk, G., Liebkind, K., \& Vedder, P. (2001). Ethnic identity, immigration, and well-being: An interactional perspective. Journal of Social Issues, 57(3), 493-510. http://dx.doi.org/10.1111/0022-4537.00225

Pollock, D. C., \& Van Reken, R. E. (2009). Third culture kids: growing up among worlds: Boston/London: Nicholas Brealey Publishing.

Prieur, A. (2004). Balansekunstnere. Betydningen av innvandrerbakgrunn i Norge. Oslo: Pax.

Rolvsjord, R. (2004). Therapy as Empowerment. Clinical and Political Implications of Empowerment Philosophy in Mental Health Practises of Music Therapy. Nordic Journal of Music Therapy, 13(2), 99-111. http://dx.doi.org/10.1080/08098130409478107

Salole, L. (2013). Krysskulturelle barn og unge. Om tilhørighet, anerkjennelse, dilemmaer og ressurser. Oslo: Gyldendal Akademisk.

Salole, L., \& Van der Weele, J. (2010). Oppvekst i mellomland. Psykologiske perspektiver på et liv i bevegelse og stillstand. In T. S. Drønen \& M. Skjortnes (Eds.), Med hjertet på flere steder. Om barn, misjon og flerkulturell oppvekst (pp. 347-366). Trondheim: Tapir akademisk forlag.

Sam, D. L., \& Oppedal, B. (2003). Acculturation as a developmental pathway. Online readings in psychology and culture, $8(1), 6$.

http://dx.doi.org/10.9707/2307-0919.1072

Schandy, K. (2013). 'Jeg er en påfugl': En studie om krysskulturell ungdom og et tiltak. (Master of Psychology), University of Oslo.

Schriever, M. (2011). § bli sett, hørt og akseptert: Kunst- og uttrykksterapi i et kommunalt tilbud for mindreårige (enslige) flyktningjenter. Tidsskrift for psykisk helsearbeid, 8(02), 131-141.

Schuff, H. M. T. (2013). Veier videre. Forsoning i krigsflyktningers liv. In Schuff, H., Salvesen, R., and Hagelia, H. (eds.): Forankring og fornyelse : festskrift for Ansgarskolen 1913-2013 (pp. 252-271). Kristiansand: Portal forlag.

Schuff, H. M. T. (2014). Inclusion and participation in a multicultural gospel choir. In FLEKS - Scandinavian Journal of Intercultural Theory and Practice (Vol. 1/2014). http://dx.doi.org/10.7577/fleks.1228

Selle, H. S., Østby, K., \& Reif, H. (2001/2015). FLEXid. Retrieved 05.08.2013, 2013, from www.flexid.no

Simon, B. (2004). Identity in Modern Society. A Social Psychological Perspective. Oxford/Malden/Carlton: Blackwell Publishing. http://dx.doi.org/10.1002/9780470773437

Sveaass, N. (2000). Restructuring meaning after uprooting and violence: psychosocial interventions in refugee receiving and in post-conflict societies. (PhD), University of Oslo.

Tajfel, H., \& Turner, J. C. (2004). The Social Identity Theory of Intergroup Behavior. In Jost, John T. Sidanius, Jim (Eds.): Political psychology: Key readings. Key readings in social psychology (pp. 276-293). New York, NY, US: Psychology Press. 
Teodorescu, D.-S., Heir, T., Hauff, E., Wentzel-Larsen, T., \& Lien, L. (2012). Mental health problems and post-migration stress among multi-traumatized refugees attending outpatient clinics upon resettlement to Norway. Scandinavian Journal of Psychology, (53), 316-332. http://dx.doi.org/10.1111/j.1467-9450.2012.00954.x

Thomas, W. I., \& Thomas, D. S. (1928). The Child in America. New York: Alfred A: Knopf. Valsiner, J. (2014). An invitation to cultural psychology. Los Angeles/London/New Delhi: Sage. http://dx.doi.org/10.4135/9781473905986 
i I wish to thank Lill Salole at Krysskultur for her valuable comments and input to this manuscript.

ii I prefer "cross-cultural" to "multicultural" in this case, since one could argue that the former term highlights the often criss-crossing and flexible trajectories of lives among cultures, while the latter could be understood as if a person's cultures were clearly distinguishable and quantifiable. Cf. also Salole (2013) for a similar argument.

iii Øia (2007:124) states that first-generation immigrants and those from mixed backgrounds (one Norwegian parent and one foreign-born parent) seem to experience more mental distress. No significant differences were found between Norwegian young people and Norwegian-born young people with immigrant parents.

iv In addition to the Kaleidoscope/Fargespill concept and trademark, a smaller-scale version known as Flere farger (More colours) has been developed, suitable for smaller communities/locations with fewer resources. 